\title{
Effects of Prompt Squatting on the Systolic Murmur in Idiopathic Hypertrophic Obstructive Cardiomyopathy*
}

\author{
M. NELLEN, M.D., F.R.C.P., F.R.C.P.ED., F.A.C.C. ; M. S. GOTSMAN, M.D., M.R.C.P., M.R.C.P.GLASG. \\ L. VOGELPOEL, M.D., M.R.C.P. ; W. BECK, M.SC., M.MED., M.R.C.P. \\ V. SCHRIRE, M.SC., PH.D., M.D., F.R.C.P., F.R.C.P.ED., F.A.C.C.
}

Brit. med. F., 1967, 3, 140-143

In patients with hypertrophic obstructive cardiomyopathy obstruction to left ventricular ejection varies from moment to moment. The pressure gradient can be increased by amyl nitrite, which lowers peripheral resistance (Braunwald and Ebert, 1962 ; Wigle et al., 1965 ; Hancock and Fowkes, 1966), or can be reduced or abolished by systemic vasoconstriction with phenylephrine, methoxamine, or angiotensin (Braunwald and Ebert, 1962 ; Braunwald et al., 1964a ; Wigle et al., 1965) or by aortic constriction (Pierce et al., 1964). Inotropic agentsdigitalis and isoprenaline-increase the obstruction by increasing the vigour of ventricular contraction; this effect can be prevented by drugs which block the sympathetic beta-receptors (Braunwald and Ebert, 1962 ; Braunwald et al., 1962 ; Harrison et al., 1964). Reduction in circulating blood volume and the Valsalva manœuvre reduce ventricular volume, increase contractility, and increase the obstruction (Braunwald et al., 1964b ; Marcus et al., 1964 ; Shah et al., 1965a, 1965b). During these manipulations of the circulation the murmur varies in intensity, becoming louder with more severe obstruction, and can be

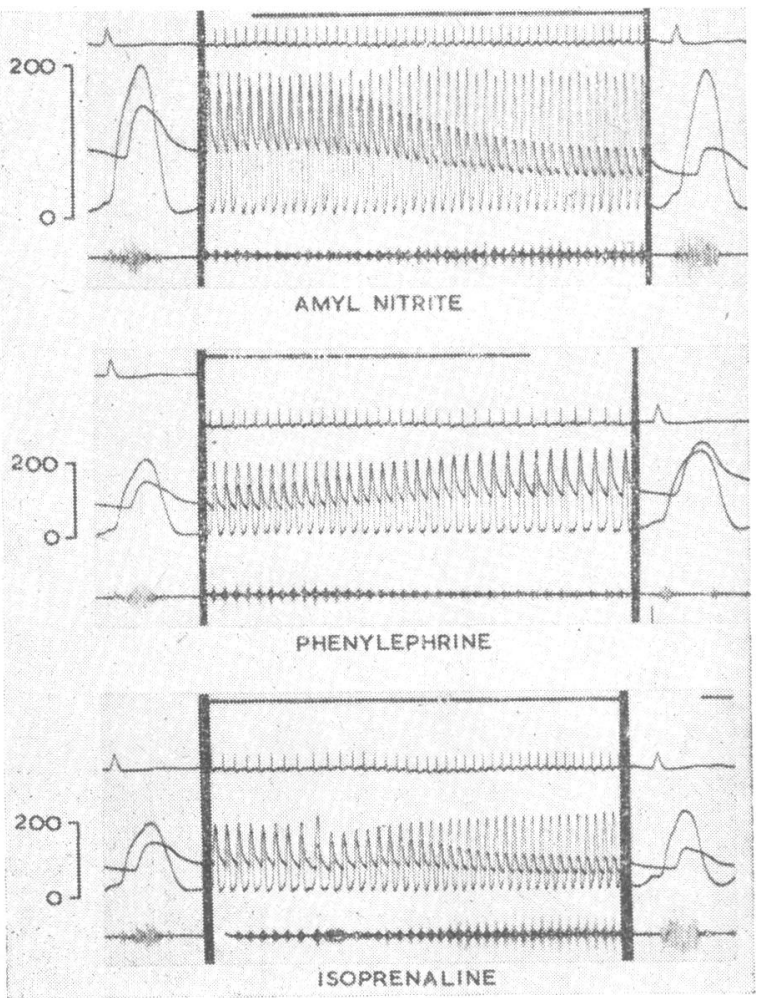

FIG. 1.-Hypertrophic obstructive cardiomyopathy. The systolic murmur reflects the haemodynamic situation with amyl nitrite, phenylephrine, and isoprenaline. Pressure measurements in left ventricle and femoral artery. Simultanecus external phonocardiceram shown in lower channel.

- From the Cardiac Clinic, Department of Medicine, University of Cape Town, and the Cardiovascular-Pulmonary Research Group, sup-
ported in the Department of Medicine by the Council for Scientific and Industrial Research. virtually abolished when the gradient disappears (Goodwin, 1964 ; Nellen et al., 1965) (Fig. 1), thus reflecting the haemodynamic situation.

Squatting provides a simple bedside method of acutely increasing venous return, effective filling pressure of the heart, stroke output, and systemic arterial pressure (Sharpey-Schafer, 1956). We have therefore studied the effect of this manoeuvre on the systolic murmur in 11 patients with hypertrophic obstructive cardiomyopathy, and report the results in this paper. This effect has been compared with that from eight patients who have fixed valvar aortic stenosis and five patients with mitral incompetence, as the murmur in these cases may resemble that of hypertrophic obstructive cardiomyopathy. In addition, to help us in assessment of the mechanism of squatting we studied the effect of this procedure on the murmur of pulmonary stenosis.

\section{Patients and Methods}

In 11 patients the clinical diagnosis of hypertrophic obstructive cardiomyopathy was confirmed by cardiac catheterization cineangiocardiography, and the dynamic response to manipulation of the circulation by drugs affecting the severity of the left ventricular obstruction (Braunwald et al., 1964a). The peat systolic pressure gradient between the inflow and outflow tracts of the right ventricle (intraventricular gradient) was measured. Mitral incompetence was assessed on cineangiocardiography. The clinical and haemodynamic features in each patient are given in Table I. In one patient (Case 10) the diagnosis was made on clinical grounds and by the typical response of the murmur to vasoactive drugs (Nellen et al., 1965). Auscultation and phonocardiography were performed with the patient in the standing and squatting position, and the intensity and length of the systolic murmur was noted. Phonocardiograms were recorded on an Elema Mingograph 4 channel recorder (moving magnet ink jet galvanometers). Systemic arterial pressure was measured simultaneously with a cuff sphygmomanometer in both positions.

Squatting had to be prompt to achieve the optimum results. The patient was told to hold the edge of the examining couch while squatting. The stethoscope or phonocardiograph microphone was applied to the chest at the site of maximum intensity of the murmur, and the investigator then squatted rapidly and promptly with the patient, listening to the intensity of the murmur during held expiration. Prolonged breath-holding was avoided.

Eight patients with discrete valvar aortic stenosis and without mitral valve disease were studied for comparison of the effect of squatting on the systolic murmur. The clinical details of these cases and the results of cardiac catheterization and cineangiocardiography are given in Table II. The diagnosis has been confirmed at operation. Five cases with rheumatic mitral incompetence were diagnosed clinically by accepted criteria and the effect of squatting on the systolic murmur was also studied. Three cases of moderate pulmonary stenosis proved by catheterization were also investigated. 


\section{Results}

There was a rise in arterial and pulse pressure on squatting in each patient with hypertrophic obstructive cardiomyopathy. After 5-10 beats bradycardia occurred. The systolic murmur was promptly abolished in two and shortened and softened markedly in intensity in seven of the patients (Table I, Fig 2). In Case 10 the systolic murmur softened slightly-this patient was on a full dose of propranolol. In Case 11 the response was variable. The first heart sound usually softened and broadened. The second heart sound was unaltered or increased slightly in intensity. A fourth heart sound was recorded in five patients while standing. In three it moved towards the first sound, while in the other two there was little change in relation to the first sound on squatting. In no case did the murmur intensify.

In our studies of valvar aortic stenosis we found a similar increase in blood pressure and bradycardia, but the systolic murmur increased in intensity and length in six of the eight

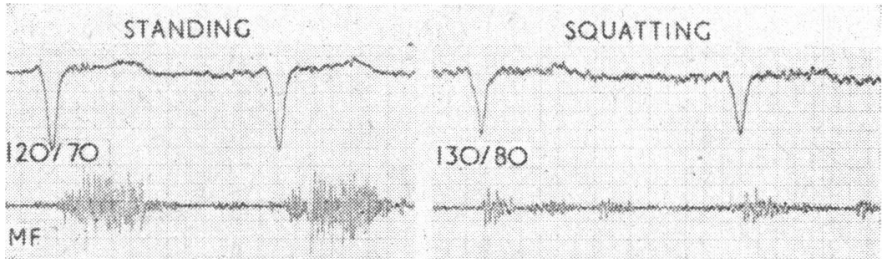

FIG. 2.-Case 3. Hypertrophic obstructive cardiomyopathy. Phonocardiogram (M.F.=medium frequency) taken medial to the apex. The systolic murmur is virtually abolished on squatting. (Lead $V_{1}$ of the electrocardiogram is indicated in the top tracing. Each large square on the record indicates 0.05 second.)

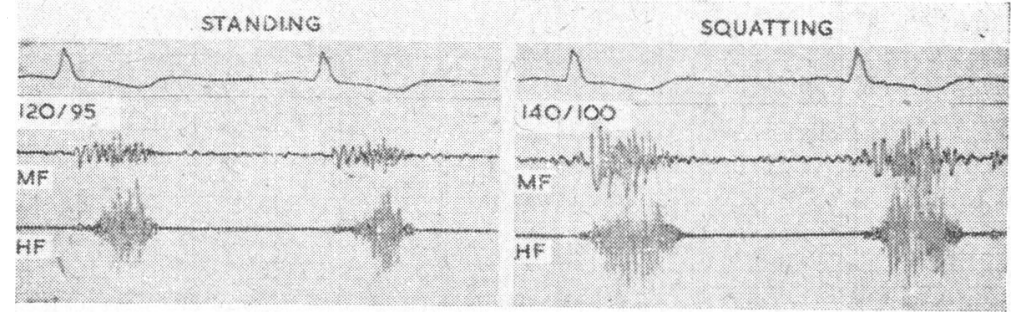

FIG. 3.-Case V. Valvar aortic stenosis. Phonocardiogram taken at the aortic area. The systolic murmur increases in intensity on squatting. (Upper tracing shows lead
I of the electrocardiogram. M.F.= medium frequency; H.F.= high-frequency phonocardiogram.)
phon

patients (Table II, Fig. 3). In the other two the change was insignificant. These two latter patients had poor left ventricular function as assessed by an elevated end-diastolic pressure in the left ventricle, left ventricular pulsus alternans, and an enlarged ventricle contracting poorly at cineangiocardiography.

In five patients with rheumatic mitral incompetence the systolic murmir increased definitely but slightly on squatting. The third heart sound and mid-diastolic flow murmur also increased in intensity (Fig. 4). In three cases the systolic murmur of pulmonary stenosis intensified appreciably on squatting (Fig. 5).
It has been shown (Sharpey-Schafer, 1956) that when normal subjects squat arterial mean pressure increases. The increase is greatest after a few seconds; thereafter mean pressure falls and eventually stabilizes at a level higher than the standing or sitting

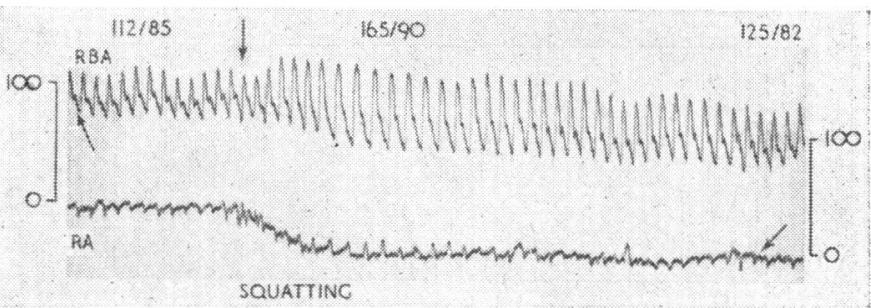

FIG. 6.-Effect of squatting on the arterial and right atrial pressure of a subject with mild pulmonary stenosis. Right atrial pressure increases very slightly on squatting. Mean arterial and pulse pressure increase, but there is a later fall and bradycardia from the baroceptor response; pulse and mean pressure are still greater than control values. (Zero level taken at the sternal angle in each position. Left-hand scale shows pressures in mm.Hg while standing and right-hand scale shows pressures on squatting.)

level. This we have confirmed (Fig. 6). The immediate rise in arterial pressure is believed to have two causes, the major factor being an increase in stroke output due to an increase in effettive cardiac filling pressure, which in turn is due to squeezing blood out of the veins of the legs. The second factor, a minor one, is a small increase in peripheral arterial resistance due to the hydrostatic effect of the posture change and kinking of the femoral arteries. After a few seconds mean arterial pressure falls slightly owing to peripheral dilatation and stabilizes at a new level which is still higher than the control value. Bradycardia also occurs. This is a delayed baroceptor response. The slowing of the heart rate occurs at the highest blood pressure levels, but the changes in mean pressure and pulse pressure are still present if no rate changes occur, as in thyrotoxicosis or after atropine (Sharpey-Schafer, 1956). Squatting is thus an excellent procedure for increasing the effective filling pressure of the heart acutely; it is the converse of the Valsalva manœuvre (SharpeySchafer, 1955, 1956). This has been confirmed by Brotmacher (1957a, 1957b), who also demonstrated an increase in right atrial and pulmonary capillary wedge pressure when patients squat in the lying position. However, simultaneous oesophageal pressure was not measured in his cases.

Similar studies by O'Donnell and McIlroy (1959) confirm Sharpey-Schafer's findings. They also showed that when subjects squat in a swimming-pool, so that the effect of gravity is removed, the haemodynamic response does not occur. A sudden increase in venous return and effective cardiac filling pressure would appear to be the cause of the increase in intensity of the systolic murmur in our cases of pulmonary stenosis. Increased peripheral resistance would not be a factor here. Our findings
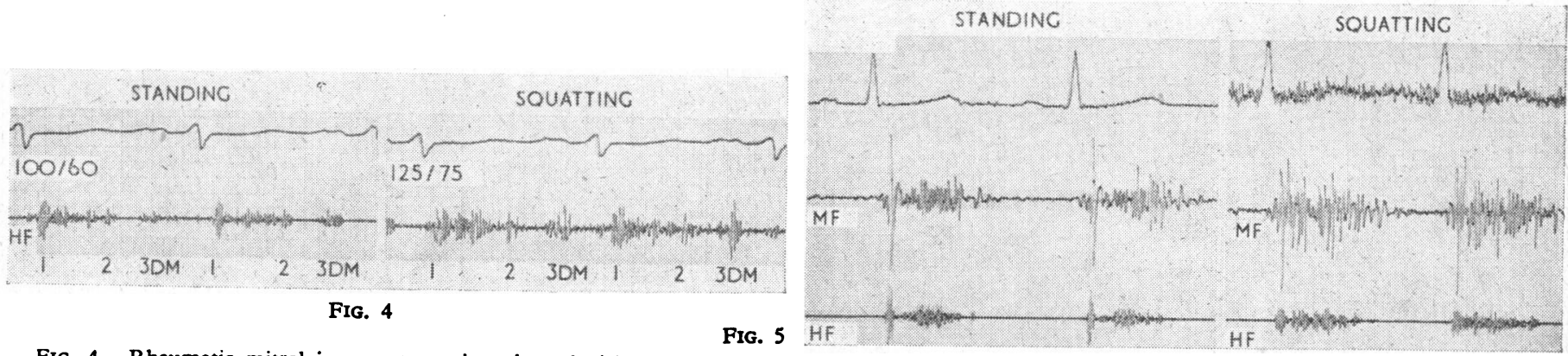

Fig. 5

Fig. 4.- Rheumatic mitral incompetence in coloured girl aged 16. Phonocardiogram taken at the mitral area. The systolic murmur, third heart sound (3), and mid-diastolic murmur (D.M.) intensify on squatting. ( $1=$ first heart sound ; $2=$ second heart sound. Upper tracing shows standard lead I of the electrocardiogram.) FIG. 5. - Moderate pulmonary stenosis in European boy aged 9 . Phonocardiogram taken at second left intercostal space. The systolic murmur intensifies on squatting. (Standard lead II of the electrocardiogram shown in upper tracing.) 
TABLE I.-Clinical and Haemodynamic Data on 11 Cases of Hypertrophic Obstructive Cardiomyopathy with the Effect of Squatting on the Blood Pressure and Systolic Murmur

\begin{tabular}{|c|c|c|c|c|c|c|c|c|c|c|c|c|}
\hline \multirow[t]{2}{*}{$\begin{array}{l}\text { Case } \\
\text { No. }\end{array}$} & \multirow{2}{*}{\multicolumn{2}{|c|}{$\begin{array}{l}\text { Age } \\
\text { and } \\
\text { Sex }\end{array}$}} & \multirow[t]{2}{*}{ Race } & \multicolumn{4}{|c|}{$\begin{array}{l}\text { Peak Systolic Pressure } \\
\text { Gradient between L.V. and F.A. } \\
\text { (mm. Hg) }\end{array}$} & \multirow{2}{*}{$\begin{array}{c}\text { Intra- } \\
\text { ventricular } \\
\text { Gradient } \\
\text { in R.V. } \\
\text { (mm. Hg) } \\
\end{array}$} & \multirow[t]{2}{*}{$\begin{array}{l}\text { M.I. } \\
\text { (Cine) }\end{array}$} & \multicolumn{2}{|c|}{$\begin{array}{l}\text { Blood Pressure } \\
\text { (mm. Hg) }\end{array}$} & \multirow{2}{*}{$\begin{array}{c}\text { Effect } \\
\text { of } \\
\text { Squatting on } \\
\text { Intensity of } \\
\text { Murmur } \\
\end{array}$} \\
\hline & & & & Rest & AN & PE & ISOP & & & Standing & Squatting & \\
\hline $\begin{array}{r}1 \\
2 \\
3 \\
4 \\
5 \\
6 \\
7 \\
8 \\
9 \\
10\end{array}$ & $\begin{array}{l}57 \\
66 \\
59 \\
48 \\
35 \\
44 \\
54 \\
51 \\
41 \\
25\end{array}$ & $\begin{array}{c}M \\
F \\
F \\
F \\
M \\
M \\
M \\
F \\
F \\
F\end{array}$ & $\begin{array}{l}\mathbf{E} \\
\mathbf{E} \\
\mathbf{E} \\
\mathbf{C} \\
\mathbf{E} \\
\mathbf{E} \\
\mathbf{E} \\
\mathbf{E} \\
\mathbf{E} \\
\mathrm{E}\end{array}$ & $\begin{array}{r}20 \\
5 \\
110 \\
5 \\
15 \\
0 \\
42 \\
18 \\
10 \\
0\end{array}$ & $\begin{array}{r}92 \\
130 \\
22 \\
62 \\
20 \\
104 \\
40 \\
40 \\
-\end{array}$ & $\begin{array}{l}\frac{0}{0} \\
\frac{0}{-} \\
\frac{0}{10} \\
5 \\
-\end{array}$ & $\begin{array}{r}82 \\
115 \\
175 \\
33 \\
105 \\
\frac{120}{120} \\
\frac{55}{-}\end{array}$ & $\begin{array}{r}3 \\
0 \\
7 \\
0 \\
4 \\
0 \\
10 \\
7 \\
0 \\
-\end{array}$ & $\begin{array}{l} \pm \\
0 \\
\pm \\
\pm \\
+ \\
0 \\
\pm \\
0 \\
-\end{array}$ & $\begin{array}{r}130 / 90 \\
140 / 80 \\
110 / 65 \\
110 / 65 \\
110 / 80 \\
130 / 90 \\
80 / 60 \\
125 / 70 \\
80 / 60 \\
110 / 60\end{array}$ & $\begin{array}{l}140 / 95 \\
160 / 90 \\
195 / 100 \\
125 / 70 \\
130 / 100 \\
150 / 100 \\
130 / 60 \\
150 / 75 \\
100 / 60 \\
120 / 70\end{array}$ & 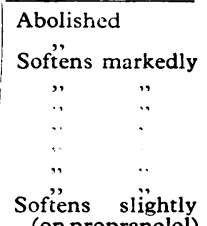 \\
\hline 11 & 26 & $M$ & C & 70 & 110 & 55 & - & 0 & + & $90 / 70$ & $110 / 60$ & $\begin{array}{l}\text { (on prop } \\
\text { Variable }\end{array}$ \\
\hline
\end{tabular}

$\mathrm{AN}=$ Amyl nitrite. $\mathrm{ISOP}=$ Isop
R.V $=$ Right ventricle. $\mathrm{E}=$ European.

TABLE II.-Clinical and Haemodynamic Information in Eight Cases of Aortic Stenosis, and Effect of Squatting on Blood Pressure and Systolic Murmur. (Poor Left Ventricular Function was Indicated by Left Ventricular Pulsus Alternans, an Elevated Enddiastolic Pressure in the Ventricle, or Impaired Ventricular Contractility Assessed by Cineangiocardiography)

\begin{tabular}{|c|c|c|c|c|c|c|c|c|c|}
\hline \multirow{2}{*}{$\begin{array}{l}\text { Case } \\
\text { No. }\end{array}$} & \multirow{2}{*}{$\begin{array}{c}\text { Age } \\
\text { and Sex }\end{array}$} & \multirow{2}{*}{ Race } & \multirow{2}{*}{$\begin{array}{c}\text { Pressure } \\
\text { Gradient } \\
\text { Across AO. } \\
\text { Valve (mm. Hg) }\end{array}$} & \multirow{2}{*}{$\underset{\substack{\text { Cardiac } \\
\text { Index } \\
\text { M./min./ } \\
\text { M. } .^{2}}}{ }$} & \multirow{2}{*}{$\begin{array}{c}\text { AO } \\
\text { Valve } \\
\text { Area } \\
\text { (sq. cm.) }\end{array}$} & \multirow{2}{*}{$\begin{array}{l}\text { L.V. } \\
\text { Function }\end{array}$} & \multicolumn{2}{|c|}{$\begin{array}{c}\text { Blood Pressure } \\
(\mathrm{mm} . \mathrm{Hg})\end{array}$} & \multirow{2}{*}{$\begin{array}{l}\text { Effect of } \\
\text { Squatting on } \\
\text { Intensity of } \\
\text { Murmur }\end{array}$} \\
\hline & & & & & & & Standing & Squatting & \\
\hline $\begin{array}{c}\text { II } \\
\text { III } \\
\text { IV } \\
\text { V } \\
\text { VI } \\
\text { VII } \\
\text { VIII }\end{array}$ & $\begin{array}{rl}63 & M \\
26 & F \\
8 & M \\
61 & M \\
61 & M \\
17 & M \\
43 & M \\
63 & M\end{array}$ & $\begin{array}{l}\mathbf{E} \\
\mathbf{C} \\
\mathbf{E} \\
\mathbf{E} \\
\mathbf{E} \\
\mathbf{E} \\
\mathbf{E} \\
\mathbf{E}\end{array}$ & $\begin{array}{r}115 \\
117 \\
45 \\
115 \\
94 \\
120 \\
80\end{array}$ & $\begin{array}{l}1 \cdot 8 \\
2 \cdot 8 \\
4 \cdot 2 \\
3 \cdot 3 \\
3 \cdot 9 \\
5 \cdot 1 \\
3 \cdot 4 \\
1 \cdot 3\end{array}$ & $\begin{array}{l}0.4 \\
0.5 \\
0.7 \\
0.5 \\
0.4 \\
0.5 \\
0.7\end{array}$ & $\begin{array}{l}\text { Normal } \\
\text { ", } \\
\text { Poor } \\
\text { Normal } \\
\text { Poor } \\
\text { ", }\end{array}$ & $\begin{array}{l}100 / 75 \\
120 / 70 \\
90 / 60 \\
160 / 100 \\
120 / 95 \\
90 / 60 \\
115 / 85 \\
145 / 95\end{array}$ & $\begin{array}{l}120 / 100 \\
130 / 80 \\
110 / 60 \\
180 / 110 \\
140 / 100 \\
110 / 70 \\
120 / 80 \\
150 / 100\end{array}$ & $\begin{array}{c}\text { Increases } \\
\text { ”, } \\
, " \\
\text { ” } \\
\text { Little change } \\
\text { Little change, alter- } \\
\text { nans abolished }\end{array}$ \\
\hline
\end{tabular}

in hypertrophic obstructive cardiomyopathy can similarly be explained by an increase in venous return which increases left ventricular filling and end-diastolic volume-an effect similar to a rapid infusion of blood or fluid or tilting the patient into a head-down position (Braunwald et al., 1964a ; Shah et al., 1965a; Mason et al., 1966).

With a larger intraventricular volume, the gradient lessens so that the stroke volume and mean arterial pressure increase. Though " contractility" may be enhanced initially, this is overcome by the increase in ventricular dimensions which reduces the degree of obstruction. An additional factor could be the baroceptor response to the raised arterial pressure and peripheral resistance leading to bradycardia and reduction of left ventricular contractility - a negative inotropic effect. A similar response to induced hypertension occurs during phenylephrine infusion, which diminishes the murmur of hypertrophic obstructive cardiomyopathy (Harrison et al., 1964 ; Nellen et al., 1965 ; Lewis et al., 1965). These three factors-increased end-diastolic volume bradycardia, and reduced contractility-reduce the abnormal dynamic obstruction in the left ventricle. The systolic murmur, reflecting the intraventricular gradient, softens.

The murmur in hypertrophic obstructive cardiomyopathy can possibly be attributed to two other factors, obstruction to right ventricular outflow and mitral incompetence. In the present group of patients systolic pressure gradients within the cavity of the right ventricle were too small to account for the significant murmurs. Criley et al. (1965) suggested that the murmur is due to mitral incompetence from abnormally aligned papillary muscles in the small end-systolic cavity. We have assessed the degree of mitral incompetence from the cineangiocardiograms of our patients. In each patient reflux of dye into the left atrium was present, but this was often observed during diastole or during ventricular premature systoles, so that the degree of true incompetence was difficult to estimate. Our studies, in patients with hypertrophic obstructive cardiomyopathy, of the simultaneous response of the murmur and the pressure gradient within the left ventricle, recorded during manipulation of the circulation, indicate that the intensity of the murmur is related to the pressure gradient recorded (Nellen et al., 1965). This suggests that the intraventricular obstruction is the most likely cause of the murmur, though mitral incompetence from abnormally aligned papillary muscles cannot be excluded.

The hypothesis of increased venous return can also explain the effect of squatting on the systolic murmur of aortic and pulmonary stenosis. This increases the stroke output of the left ventricle, more blood is ejected through a constant orifice per unit time, the velocity of flow is increased, and the murmur becomes louder and longer. If ventricular function is compromised, however, the stroke output increase does not occur (Thomas and Shillingford, 1965). A similar mechanism may apply to rheumatic mitral incompetence. The augmented venous return increases forward flow across the mitral valve, and hence the mid-diastolic flow murmur and third heart sound increase in intensity. The systolic murmur also increases slightly in loudness.

The softening of the murmur in squatting is thus a useful bedside test for recognizing hypertrophic obstructive cardiomyopathy. It increases significantly in intensity in the majority of patients with valvar aortic stenosis and slightly in mitral incompetence.

\section{Summary}

In 8 out of 11 patients with hypertrophic obstructive cardiomyopathy the systolic murmur softened and shortened in length with prompt squatting, while in two it was abolished.

In six out of eight patients with discrete valvar aortic stenosis there was an increase in intensity and duration of the systolic murmur on squatting. A similar but much less striking increase was observed in five subjects with mitral incompetence.

The response of the systolic murmur in hypertrophic obstructive cardiomyopathy to prompt squatting is a useful aid to bedside clinical diagnosis.

We wish to thank Dr. W. Beck, our colleagues in the cardiac clinic, and our laboratory staff for assistance with the catheterization procedures, and Dr. J. G. Burger, Superintendent of Groote 
Schuur Hospital, for permission to publish. We acknowledge with thanks the continued financial support of the Council for Scientific and Industrial Research and the City Council of Cape Town.

\section{REFERENCES}

Braunwald, E., Brockenbrough, E. C., and Frye, R. L. (1962). Circulation, 26, 166

— and Ebert, P. A. (1962). Amer. f. Cardiol., 10, 489.

- Lambrew, C. T., Rockoff, S. D., Ross, J., and Morrow, A. G. (1964a). Circulation, 30, Suppl. No. 4, p. 3.

(1964a). Circulation, 30, Suppl. No. 4, p. 3. J. W., Mason, D. T., Ond Fort, L., III (1964b). Ibid., 29, 422. Brotmacher, L. (1957a). Brit. heart F., 19, 559.

Brotmacher, L. (1957a). Brit.

Criley, J. M., Lewis, K. B., White, R. I., and Ross, R. S. (1965). Circulation, 32,881 .

Goodwin, J. F. (1964). Brit. med. f., 1, 1527.

Hancock, E. W., and Fowkes, W. C. (1966). Circulation, 33, 383.
Harrison, D. C., Braunwald, E., Glick, G., Mason, D.T., Chidsey, C. A., and Ross, J., jun. (1964). Ibid., 29, 84.

Lewis, R. P., Bristow, J. D., Farrehi, C., Kloster, F. E., and Griswold, H. E. (1965). Amer. F. Med., 38, 842.

Marcus, F. I., Westura, E. E., and Summa, J. (1964). Amer. Heart f.,

Mason, D. T., Braunwald, E., and Ross, J., jun. (1966). Circulation, 33, 374.

Nellen, M., Beck, W., Vogelpoel, L., Swanepoel, A., and Schrire, V. (1965). S. Afr. med. 尹., 39, 304.

O'Donnell, T. V., and Mcllroy, M. B. (1962). Amer. Heart F., 64, 347. Pierce, G. S., Morrow, A. G., and Braunwald, E. (1964). Circulation, 30, Suppl. No. 4, p. 152.

Shah, P. M., Amarasingham, R., and Oakley, C. M. (1965a). Brit. Heart Ұ., 27, 83 .

Yipintsoi, T., Amarasing

Sharpey-Schafer, E. P. (1955). Brit. med. 7., 1, 693.

Sharpey-Schafer, E. P. (1955)
(1956). Ibid., 1, 1072

Thomas, M., and Shillingford, J. (1965). Brit. Heart 7., 27, 17.

Wigle, E. D., David, P. R., Labrosse, C. J., and McMeekan, J. (1965) Amer. f. Cardiol., 15, 761 .

\title{
Reduction of Clotting in Scribner Shunts by Long-term Anticoagulation
}

\author{
A. J. WING,* M.A., B.M., M.R.C.P. ; J. R. CURTIS, † M.B., B.S., M.R.C.P. \\ H. E. DE WARDENER, $\ddagger$ M.B.E., M.D., F.R.C.P.
}

Brit. med. . ., 1967, 3, 143-145

Drukker et al. (1966) reported that 612 patients had been placed on regular dialysis treatment programmes in Europe by May 1966. For all these patients the Achilles heel of the treatment remains the arteriovenous shunt. The "life" of the shunts varies from centre to centre. Mean survival rates of between 2 and 14 months have been reported (Ramirez et al., 1966 ; Pendras and Smith, 1966).

Shunt life is influenced by infection and clotting. There have been six infections in 164 patient-years' experience in this unit. The frequency of clotting incidents is much higher ; 59 during the same period (cf. Erickson et al., 1966). This represents one clotting incident every 3.3 patient-months. At this rate, in a 10-bedded unit treating 30 patients 109 such incidents could be expected in the course of one year's operation.

When a shunt has clotted, declotting is necessary. Both events must be assumed to cause damage to the cannulated vessels. The clot causes anoxia to the intima, and the declotting procedure may traumatize the vessels. In addition it exposes the cannula site to the risks of infection. The risk of serious complications due to embolism appears to be slight. Clots are often released into the circulation at this procedure, and, despite the frequency with which it is carried out, there have been only isolated reports of collapse (Sokol, 1964) and of infected pulmonary emboli (Pendras and Erickson, 1965). Death has occurred on three occasions, each in a different unit, after declotting of arterial cannulae. Each patient became deeply unconscious after the procedure and some cerebral incident seems to have occurred. In our unit declotting is not carried out by the patients themselves and therefore they must come to the unit when they find that their shunt has clotted. A clotted shunt induces anxiety in the patient, for it is often the first of a series of clotting episodes and may be the signal that the cannula is coming to the end of its life. The significance

\footnotetext{
* Senior Registrar.

+ Lecturer in Medicine.

Department of Medicine, Charing Cross Hospital Medical School, Fulham Hospital, London W.6.
}

of the loss of a cannula does not escape these patients. Clotting episodes place demands on the staff " on call," and the incidence of such episodes dictates in part the staff requirements for these units.

Long-term oral anticoagulation with warfarin sodium has been given to some of our patients. This communication reports the results so far.

\section{Methods}

Anticoagulants are not given to any patient until a clotting episode has occurred. Therefore, after their original cannulation the patients are included in the untreated group. When a clot occurs oral anticoagulants are begun. Warfarin sodium is used and the prothrombin time is kept at 1.5 times the control time. Prothrombin times are estimated by Quick's one-stage method with the use of lung thromboplastin (Geigy). A loading dose of $30 \mathrm{mg}$. is given and 48 hours later a maintenance dose is prescribed. The maintenance dose required by our patients is in the range of 3-12 mg. a day. During the first 48-hour period 5,000 units (50 mg.) of heparin is injected six-hourly by the patient himself into the shunt through a medicated sleeve described elsewhere (Evans, 1966). If further clotting occurs despite adequate anticoagulation, a venogram is obtained. If there is reason to suspect that the arterial cannula is at fault -that is, poor flows during dialysis without high pressure in the "venous" line-an arteriogram is also obtained. If angiography shows an obvious cause for clotting or poor flows, then surgical correction is necessary.

Because of this method of selection the treated group is made up of patients who have shown themselves to be at risk, and therefore includes patients whose cannulae have already been damaged by at least one clotting episode. The untreated group is made up of patients whose shunts have never clotted, and also includes those patients whose anticoagulants have been discontinued. 